\title{
Uma breve análise do material didático de língua italiana criado para o Centro de Estudo de Línguas da Secretaria de Educação do Estado de São Paulo
}

\author{
Aline Cristiane Peleteiro \\ Aluna de mestrado no programa de Pós-Graduação em Língua, Literatura e Cultura italiana na \\ Universidade de Filosofia Ciências, Letras e Ciências Humanas (USP) \\ alinepeleteiro@usp.br
}

Resumo: Observando as relações políticas, econômicas e culturais entre o Brasil e a Itália, podemos notar que um grande número de pessoas procura aprender o idioma italiano para resgatar suas raízes, buscar novas oportunidades acadêmicas, de trabalho, turismo ou por simples prazer em aprender um novo idioma. Alguns buscam cursos particulares de língua, entretanto, no estado de São Paulo, os alunos de rede pública de ensino têm a oportunidade de aprender gratuitamente o idioma italiano, através do CELCentro de Estudo de Línguas. Este artigo tem como objetivo fazer uma breve análise de como o recente material produzido para o Centro de Estudos de Línguas, doravante chamado de $\boldsymbol{C E} \boldsymbol{L}$, utiliza a abordagem comunicativa e os princípios do pós-método. Primeiramente, com o intuito de situar o leitor, será esclarecido o funcionamento dos $\mathrm{Cel}$, em seguida será discutida a abordagem comunicativa e o pós-método e finalmente como essa abordagem se apresenta no novo material produzido para os alunos adolescentes do CEL. O material desenvolvido para os Cel revelou-se uma importante ferramenta de apoio ao professor para direcionar suas aulas e refletir sobre a própria prática.

Palavras-chave: Ensino de Italiano. Produção de material didático. Abordagem comunicativa. Pós-método. 
Abstract: Osservando le relazioni culturali, politiche ed economiche tra Brasile e Italia, possiamo dire che un grande numero di persone cercano di imparare la lingua italiana in Brasile, sia per cercare nuove opportunità academiche, di lavoro, o anche per ricuperare le sue radici culturali, per turismo o solo per il piacere di imparare un nuovo idioma. La grande parte delle persone lo fanno in corsi di lingua particolari, ma allo Stato di San Paolo, gli adolescenti hanno l'opportunià di impararla nei Centri di Studi di Lingue dello Stato gratuitamente. Quest'articolo intende fare una breve descrizione e analise di come il nuovo materiale didattico prodotto dagli insegnanti dell' USP per questi Centri di Studi di Lingua CEL utilizza l'approccio comunicativo e il principio del post-metodo. Anzitutto, con lo scoppo di situare i lettori, sarà detto come funzionano questi Centri statali e poi si farà una descrizione dell'approccio comunicativo e del post-metodo e finalmente come questi due si presentano nel materiale prodotto per studenti adolescenti del CEL. Il materiale svolto per il CEL è um importante istrumento per l'insegnante nelle sue lezioni e per rifletere sulla pratica.

Parole chiave: Insegno di italiano. Produzione di materiale didattico. Approccio comunicativo. Post-metodo.

\section{Introdução}

Durante as Orientações Técnicas de língua italiana, que são cursos de reciclagem, organizados anualmente pela Secretaria de Educação para os professores do CEL, a criação de um material único de italiano a todos os CEL foi discutida com os professores da USP que ministravam o curso de reciclagem. Desta discussão surgiu a proposta da Secretaria de Educação da preparação de um material elaborado especificamente para os alunos de italiano do CEL, seguindo o modelo do material de inglês já existente que a Secretaria desenvolveu e começou a distribuir gratuitamente aos alunos.

O objetivo do presente artigo é fazer uma breve análise de como se estrutura o primeiro caderno deste recente material elaborado e quais métodos ou abordagens estão presentes. 
Uma breve análise do material didático de língua italiana criado para o Centro de Estudo de Línguas da Secretaria de Educação do Estado de São Paulo

Aline Cristiane Peleteiro

\subsection{Os Centros de Estudo de língua e a língua italiana}

Os Centros de Estudo de Línguas do Estado de São Paulo foram criados em 1987 por decreto governamental, para proporcionar ao aluno da rede estadual, gratuitamente, o acesso à língua estrangeira e o enriquecimento do currículo escolar. Inicialmente o CEL começou apenas com o espanhol e gradualmente o italiano foi implantado, assim como outras línguas como o francês, o alemão, o japonês, o mandarim, e mais recentemente, em 2004, o inglês. (São Paulo, 2009)

Até 2010, os CEL contavam com 99 unidades em todo o estado de São Paulo, pois somente cidades com mais de cem mil habitantes poderiam abrigar um CEL. Em 2011 ampliou-se esse número para 241, contemplando até mesmo cidades com menos de 50 mil habitantes. O estado de São Paulo investiu em materiais didáticos e novas tecnologias. Além disso, investiu também na formação continuada dos professores, sendo que anualmente estes são convocados, através do diário oficial, para fazer as Orientações Técnicas, que os permitem trocar experiências e aperfeiçoar-se. (São Paulo, 2009)

Os cursos de língua italiana nos CEL têm duração de três anos. Esses três anos são divididos em seis semestres chamados de estágios. O objetivo do curso é proporcionar ao adolescente, gratuitamente, um nível de comunicação eficiente para que esse aluno possa se inserir no mercado de trabalho e fazer uso prático da língua presente em seu currículo. (Informações coletadas da resolução 81/2009 da Secretaria de Educação do Estado de São Paulo que organiza o funcionamento do CEL.)

Durante as Orientações Técnicas na Escola de Formação de Professores Paulo Renata Costa Souza, em São Paulo, nos anos de 2011 e 
Uma breve análise do material didático de língua italiana criado para o Centro de Estudo de Línguas da Secretaria de Educação do Estado de São Paulo

Aline Cristiane Peleteiro

2012, discutiu-se com os professores da área de italiano da USP a necessidade de um material que atendesse à necessidade dos alunos e que fosse distribuído pela Secretaria de Educação gratuitamente seguindo o modelo do material de inglês que já existe e é distribuído semestralmente aos alunos. Todo material existente no Brasil até então era importado diretamente da Itália e não condizia com a realidade do aluno de escola pública estadual, muito menos com a realidade econômica. O livro está presente durante a aula, mas o aluno não pode ter acesso a ele fora do ambiente da sala de aula, tornando a rotina de estudos difícil e desmotivadora. Essa realidade obriga o professor a elaborar o próprio material a ser trabalhado em sala de aula.

Segundo ROQUE, SOUZA, SABINO, PINHEIRO (2004),

Ultimamente temos assistido a uma proliferação de materiais didáticos de
língua estrangeira, muitos dos quais dirigidos especificamente para o
público infantil. O que é notório, porém, é a dificuldade de se encontrar,
no Brasil, material didático voltado especificamente para o ensino da
língua italiana para crianças e, principalmente, que seja adequado aos
interesses e dificuldades de crianças falantes do português.

Durante a experiência em sala de aula, foi possível verificar que o mesmo pode-se dizer do material produzido para adolescentes. Essa é uma das razões que dificulta o aprendizado, pois sem material adequado, os alunos sentem-se desestimulados em continuar frequentando o curso. $\mathrm{O}$ aprendizado de uma língua estrangeira deve ser agradável e a procura da maioria dos alunos é pelas línguas inglesa e espanhola, pois o mercado de trabalho exige um número maior de profissionais que fale essas duas línguas. Contudo, uma parte dos alunos prefere investir na língua italiana como um diferencial em seus currículos, por interesse pessoal ou por serem descendentes de italiano. É 
Uma breve análise do material didático de língua italiana criado para o Centro de Estudo de Línguas da Secretaria de Educação do Estado de São Paulo

Aline Cristiane Peleteiro

necessário que o curso mantenha o interesse desses alunos investindo em atividades que estimulem a comunicação. ${ }^{1}$

O interesse pela língua e pela cultura italianas no estado de São Paulo, seja por razões familiares, pelo mercado de trabalho ou preferência pessoal, é notório. Como cita CASINI (2009),

A presença da cultura italiana no Brasil é bastante ampla, devido principalmente a razões históricas (a grande imigração do final do século XIX). O ensino da língua italiana está presente em todo o território brasileiro, com destaque especial para alguns Estados - em geral, aqueles para os quais dirigiu-se a maior parte dos imigrantes italianos, e onde ainda encontra-se a maior parte de seus descendentes -, em que aulas de língua italiana são ministradas a crianças e adolescentes (mas também a adultos) na própria rede pública de ensino" (p. 66).

No estado de São Paulo temos vários CEL que disponibilizam cursos de língua italiana, e a procura por parte dos alunos, apesar de pequena, existe. Enquanto 6 turmas de espanhol e 4 de inglês são criadas semestralmente, apenas uma de italiano se forma com o número mínimo de 25 alunos por turma. Muitos desses alunos, inclusive, buscam dar continuidade acadêmica ao estudo da língua após a conclusão do curso, ingressando em faculdades de Letras e tornando-se professores, pesquisadores e tradutores da língua italiana.

Com a escassez de materiais didáticos em língua italiana e a impossibilidade de adoção de um material existente por razões financeiras dos alunos, o curso do CEL seguiu por muito tempo o modelo gramáticatradução.

A apostila foi elaborada pelo aluno de mestrado e coordenador do CEL de Mirassol, Adalberto Pinheiro, com supervisão da Professora Doutora ${ }^{1}$ A autora do artigo também ministra aulas no CEL desde 2004. 
Uma breve análise do material didático de língua italiana criado para o Centro de Estudo de Línguas da Secretaria de Educação do Estado de São Paulo

Aline Cristiane Peleteiro

Fernanda Ortale da USP, em parceria com a Secretaria de Educação do Estado de São Paulo. Consequentemente, as necessidades reais dos alunos de escola pública são levadas em conta na elaboração do material, já que conta com a experiência do coordenador do CEL que também já foi professor de língua italiana e que mantém contato através das orientações Técnicas com os demais professores de italiano do estado de São Paulo. Assim, o primeiro material de língua italiana da Secretaria de Educação para os alunos do Centro de Estudos de Línguas com distribuição gratuita nasce para contribuir como suporte metodológico ao professor e proporcionar ao aluno um instrumento de comunicação e autonomia. (PINHEIRO, 2013)

\subsection{A abordagem comunicativa e a era pós-método}

Almeida Filho (1993) define: “Abordagem é o conjunto de disposições que o professor dispõe para orientar todas as ações da operação de ensinar uma língua estrangeira". Na obra de Amadeu-Sabino (1999), a autora faz referência a Brown (1987, p. 213) dizendo que é impossível resumir em uma só definição o que é a abordagem comunicativa, devido à vasta literatura na área que tentou defini-la.

Podemos apenas elencar as características desse tipo de abordagem, como faz Larsen-Freeman quando descreve os dez princípios fundamentais norteadores desse tipo de abordagem, como por exemplo, enfatizar as funções da língua acima da forma, conseguir um aluno comunicativamente competente, dentre outras. (AMADEU-SABINO, 1999)

O ensino de línguas estrangeiras no Brasil teve uma lenta evolução até chegar à abordagem comunicativa. $\mathrm{Na}$ área de língua italiana, o material usado durante muito tempo nos Centros de Línguas foram os manuais importados 
Uma breve análise do material didático de língua italiana criado para o Centro de Estudo de Línguas da Secretaria de Educação do Estado de São Paulo

Aline Cristiane Peleteiro

da Itália, como por exemplo, o livro "In Italiano", de Angelo Chiuchiu, que enfatiza o ensino da gramática e da cultura.

Historicamente o que aconteceu com o ensino de línguas no Brasil tem sido um eco do que aconteceu em outros países, geralmente com um retardo de alguns decênios, tanto em termos de conteúdo (línguas escolhidas) como de metodologia (método da tradução, método direto, etc.). O método direto, por exemplo, foi introduzido no Brasil em 1931, ou seja, 30 anos depois de sua implementação na França. (LEFFA, 1999. pp. 2-3)

Assim como aspectos importantes sobre o método de ensino foram sendo discutidos e alterados ao longo dos anos, também a ideia do que seja um indivíduo competente comunicativamente tem sido alvo de discussão. Hymes (1970), por exemplo, introduziu a noção de competência comunicativa, na qual afirma que ser competente comunicativamente vai além do conhecimento linguístico que o indivíduo pode ter, incluindo as competências sociolinguísticas, culturais, estratégicas e discursivas. Sob essa perspectiva, o objetivo do ensino de línguas passa a ser ensinar a língua em situações autênticas de comunicação e priorizar as necessidades dos alunos. Vários outros autores na década de 70 também discutiram o saber usar a língua e não apenas conhecer suas regras gramaticais, como Austin e Labov, por exemplo.

A partir de meados da década de 70 , a literatura sobre o movimento comunicativo começa a ganhar espaço, com a publicação de diversas obras importantes de autores como Hymes (1972), Willkins (1976), Widdowson (1978, 1979), Brumfit \& Johnson (1979), Savignon (1983) e outros. No entanto, por um lado, enquanto em pouco tempo já se podia encontrar no mercado uma grande quantidade de livros e artigos a respeito dessa abordagem, por outro, sua concretização em sala de aula 
Uma breve análise do material didático de língua italiana criado para o Centro de Estudo de Línguas da Secretaria de Educação do Estado de São Paulo

Aline Cristiane Peleteiro

continua sendo escassa ainda hoje, mais de duas décadas após o seu surgimento." (AMADEU-SABINO, 1994. p. 16)

Pode-se dizer que a abordagem comunicativa nasceu da necessidade dos falantes em utilizar não apenas a gramática e sim a língua em contexto real. Muitos materiais se dizem comunicativos, no entanto não há o preparo do professor para a aplicação do método (Amadeu-Sabino-1994). Como esses materiais são produzidos no exterior, algumas situações de comunicação não condizem com a realidade e as dificuldades dos alunos lusófonos. No Brasil, não se produz nenhum material em italiano voltado para adolescentes lusófonos e as necessidades dos falantes de português não são levadas em conta na elaboração do material, por isso vemos elementos nos livros didáticos, como explicações gramaticais, situações de comunicação e aspectos culturais, que são idênticos ao português e que seriam desnecessários.

Segundo Leffa (2008),

\footnotetext{
As necessidades são geralmente mais bem atendidas quando levam em consideração as características pessoais dos alunos, seus anseios, expectativas, preferência por um ou outro estilo de aprendizagem.
}

Assim, a experiência em sala de aula e as reais necessidades dos estudantes, certamente devem ser colocadas em destaque.

O fato de o método ser criado por professores do CEL para os professores do CEL colabora muito para a aplicação do material, pois o professor conhece seu público alvo e sabe das suas reais necessidades. Além disso, a Secretaria de Educação do Estado de São Paulo pretende proporcionar, através das orientações técnicas, o contato dos professores que 
Uma breve análise do material didático de língua italiana criado para o Centro de Estudo de Línguas da Secretaria de Educação do Estado de São Paulo

Aline Cristiane Peleteiro

atuam na sala de aula com aqueles que elaboraram o método para verificar a aplicabilidade em sala de aula.

O ensino comunicativo abre espaço para a espontaneidade do aluno, produzindo assim autonomia deste diante de situações reais ensinando-o a lidar com o imprevisto, o inédito, utilizando-se não somente da gramática mas de todos os aspectos que envolvem a comunicação, inclusive os aspectos culturais também presentes no material.

A linguística aplicada continua tentando decifrar o complexo processo que é o aprendizado de um segundo idioma. Nessa busca, vários autores, como Brown (1997), Kumaravadivelu (1994), Richard \& Rodgers (2001), (Apud Silva, 2004) chamam de pós-método a reflexão do professor sobre a prática e a aplicação das teorias que mais se adequem à sua realidade em sala de aula, não fixando-se apenas em um único método ou abordagem.

Segundo Kumaravadivelu o professor da era pós-método deve assim proceder:

[A]s necessidades específicas, desejos, situações, e os processos de ensino/aprendizagem, ampliação de conhecimento, habilidade e atitude para estar informado; exploração e extensão das macro-estratégias para que elas deem conta dos desafios e mudanças de contexto do ensino; desenvolvimento de micro-estratégias apropriadas para maximizar o potencial de aprendizagem na sala de aula, e monitoramento de sua habilidade de reagir as mais diversas situações de maneira significativa" (KUMARAVADIVELU, 1994. p.43 apud SILVA, G., 2004. p. 6)

Os três autores supracitados criaram estratégias que se assemelham ou se complementam para serem implementadas na sala de aula pelo professor com a finalidade de nortear seu trabalho e desenvolver uma abordagem própria baseada em métodos ou teorias pré-existentes, mas com a autonomia 
Uma breve análise do material didático de língua italiana criado para o Centro de Estudo de Línguas da Secretaria de Educação do Estado de São Paulo

Aline Cristiane Peleteiro

de direcionar sua aula de acordo com o público alvo, contexto e objetivos (SILVA, 2004).

O pós-método sugere extrair do professor um maior envolvimento no processo de reflexão sobre sua prática e, assim, adequar a metodologia segundo o objetivo que se deseja alcançar, contudo baseado em teorias préexistentes, com ênfase na comunicação e também no uso da língua, além de não desprezar as regras e as informações culturais da língua alvo.

O material desenvolvido para o CEL ajudará o professor nessa tarefa de ensinar a língua italiana, funcionando como norteador do trabalho docente e não como limitador, assim como sugere o pós-método, proporcionando ferramentas para a autonomia do professor.

\section{Breve descrição e análise da primeira unidade didática do material do CEL}

O objetivo deste artigo é colaborar com uma breve descrição e análise de como a abordagem comunicativa e o pós-método estão presentes no material. O material é composto de seis cadernos, um para cada estágio, ou seja, um para cada semestre do curso. Foi analisada apenas a primeira unidade do primeiro caderno, que se encontra em processo de finalização, mas que ainda não foi impresso e distribuído.

Um número mínimo de 20 alunos é exigido para cada estágio do CEL continuar funcionando, caso contrário, duas ou mais turmas são unidas para contemplar o número mínimo de alunos. Assim o CEL possui várias turmas multisseriadas, com dois ou até mesmo mais estágios juntos. A criação de um material específico para cada estágio do CEL proporciona uma ferramenta para resolver o antigo dilema do professor que se encontra muitas vezes 
Uma breve análise do material didático de língua italiana criado para o Centro de Estudo de Línguas da Secretaria de Educação do Estado de São Paulo

Aline Cristiane Peleteiro

diante dessas turmas multisseriadas e não sabe como proceder para não desestimular os alunos em estágios mais avançados e ao mesmo tempo estimular os que estão em estágios iniciais.

Cada caderno é composto de quatro unidades, sendo três temáticas e uma de avaliação, com textos e imagens inéditos (PINHEIRO, A. 2013). O caderno do professor contém as respostas dos exercícios e sugestões em vez de instruções de como proceder, deixando-o livre para escolher a melhor maneira de apresentar as atividades para a turma.

Cada unidade é dividida em setores que trabalham uma habilidade específica da língua. São elas: compreensão escrita, pronúncia, gramática, produção escrita e oral, cultura e compreensão oral, finalizando com sugestões de atividades online que colocam o aluno em contato direto com materiais autênticos, característica da abordagem comunicativa.

A primeira unidade se inicia com imagens que remetem à Itália e sua cultura: cappuccino, Vaticano, símbolo da Ferrari, pizza. Esse primeiro contato visual do aluno com elementos que ele reconhece também em sua cultura busca motivá-lo na aprendizagem envolvendo os alunos na lição e diminuindo a inibição do aluno.

A segunda atividade é um diálogo, onde duas pessoas na estação de trem se apresentam. Aqui a abordagem comunicativa é evidente já que privilegia o uso da língua em um contexto próximo do real.

A gramática é então apresentada ao aluno e os exercícios seguintes dão ênfase às funções da língua como leitura, compreensão e produção escrita, léxico e gramática, sempre de acordo com o eixo temático da unidade. 
Uma breve análise do material didático de língua italiana criado para o Centro de Estudo de Línguas da Secretaria de Educação do Estado de São Paulo

Aline Cristiane Peleteiro

$\mathrm{Na}$ parte "giochi di apprendimento" o aluno põe em prática a produção oral. O que ele aprendeu durante a unidade será retomado em forma de jogo; nessa parte, a autonomia do aluno se desenvolve e a comunicação entra em cena, pois ele estará utilizando o insumo aprendido para produzir sua própria comunicação dentro de um contexto real, não fazendo uso apenas de frases prontas ou repetindo sentenças sem compreender sua finalidade. Além disso, não há apenas uma possibilidade de resposta, o que limitaria o exercício a uma simples repetição.

E, por fim, a atividade online da primeira unidade é a apresentação de uma canção sobre a cultura italiana, intitulada In Italia do cantor Fabri Fibra. Esse exercício privilegia a compreensão oral dando a oportunidade ao aluno de compreender a língua como é falada por falantes nativos e, sobretudo, aproxima o aluno da realidade cultural da Itália, desconstruindo eventuais estereótipos. Afinal, a música escolhida apresenta pontos positivos e negativos a respeito da Itália. Aprender uma língua significa aprender não somente o léxico e a gramática, mas também incorporar aspectos da cultura que ela representa, e a comunicação se torna mais efetiva quando conhecemos esses aspectos culturais.

A estrutura do CEL permite esse tipo de atividade, já que cada centro se encontra dentro de uma escola estadual equipada com sala de informática e datashow, o que facilita o acesso dos alunos e do professor a esse tipo de material.

\section{Considerações finais}

O material criado para o CEL revela-se uma importante ferramenta para o professor direcionar suas aulas, pois como citam alguns professores 
Uma breve análise do material didático de língua italiana criado para o Centro de Estudo de Línguas da Secretaria de Educação do Estado de São Paulo

Aline Cristiane Peleteiro

(ROQUE, 2004) no trabalho "Criação de material didático pedagógico para o ensino de italiano a crianças e adolescentes":

Faltam, entretanto, as ferramentas de trabalho desses profissionais, ou seja, materiais didáticos de boa qualidade, preferencialmente nacionais, que possam servir-lhes de apoio para a construção de suas aulas, em seus contextos de ensino específicos, levando-se em conta as dificuldades voltadas exclusivamente ao público brasileiro.

Segundo o Quadro Comum Europeu de Referência para Línguas (2001), que determina as competências de um falante em língua estrangeira, cada falante em determinado nível deve ser capaz de se comunicar em situações específicas. Com o primeiro caderno o aluno será capaz de se comunicar no nível A1 do QCERL. Assim, é primordial que o professor tente recriar situações de comunicação mais próximas da realidade, para que o aluno aos poucos adquira o hábito de praticar a oralidade, até ter autonomia.

Com o primeiro caderno criado, este material promete ser um marco no ensino de língua italiana nas escolas públicas estaduais devido à sua importância e à distribuição gratuita na rede estadual.

\section{Bibliografia}

ALMEIDA FILHO, J. C. P. de. O Planejamento de um Curso de Língua: A Harmonia do Material-Insumo com os Processos de Aprender, Ensinar e Refletir sobre a Ação. Brasília: Universidade de Brasília, 2001.

Dimensões Comunicativas no Ensino de Línguas. Campinas: Ponte Editores, 1993.

\section{Fundamentação e crítica da abordagem comunicativa de ensino de}

línguas. Trabalhos em Linguística Aplicada, 1986. 
AMADEU-SABINO, M. O dizer e o fazer de um professor em curso de licenciatura em letras: foco na abordagem declarada comunicativa. Tese de mestrado. UNICAMP, 1994.

CASINI, M.C.; ROMANELLI, S. Ensino e pesquisa em italiano nas universidades públicas brasileiras. In Synergies Brésil n ${ }^{\circ}$ 7. São Paulo: Universidade de São Paulo e Universidade Federal de Santa Catarina, 2009. pp. 65-7.

HYMES, D. On communicative competence. In: GUMPERZ, J.J. \& HYMES, D. (Orgs.) Directions in Sociolinguistics. Nova Iorque: Holt, Rinehartand Winston, 1970.

LEFFA, Vilson J. Como produzir materiais para o ensino de línguas. In: LEFFA, Vilson J. (Org.). Produção de materiais de ensino: prática e prática. Pelotas: Educat, 2008. 2. ed.

. O ensino de línguas estrangeiras no contexto nacional. Contexturas, APLIESP, n. 4, pp. 13-24, 1999.

PINHEIRO, A. Projeto de elaboração de material didático para o curso de Língua Italiana do C.E.L. (Centro de Estudos de Línguas). "Italiano in foco", 2013.

ROQUE, A. S. de S.; SOUZA, C.L.M. de; SABINO, M.A. e PINHEIRO, P.C. Criação de Material Didático-Pedagógico para o Ensino de Italiano a Crianças e Adolescentes. Disponível em: <www.UNESP.br/>. Acesso em 23/03/2012. 
Uma breve análise do material didático de língua italiana criado para o Centro de Estudo de Línguas da Secretaria de Educação do Estado de São Paulo

Aline Cristiane Peleteiro

SILVA, G. A. A Era pós-método: o professor como um intelectual. Revista Linguagem e Cidadania, 12 ed., 2004.

Res. SE no 81/2009 - Governo do Estado de São Paulo. Disponível em <siau.edunet.sp.gov.br/ItemLise/arquivos/81_09.HTM>. Acesso em 19/02/2012. 